\title{
The significance of FMR1 CGG repeats in Chinese women with premature ovarian insufficiency and diminished ovarian reserve
}

Ruiyi Tang and Qi Yu* (D)

\begin{abstract}
Background: Previous studies have shown that there is an association between FMR1 CGG repeats and ovarian dysfunction. The aim of this study is to assess the association between the number of CGG repeats in FMR1 in Chinese patients with premature ovarian insufficiency (POI) and diminished ovarian reserve (DOR).

Methods: This is a cross-sectional, case-control study, which enrolled 124 patients with POI, 57 patients with DOR and 111 normal menopausal controls. The demographic details along with other clinical data were recorded. The FMR1 CGG repeats were analyzed by polymerase chain reaction and microfluidic capillary electrophoresis.
\end{abstract}

Results: We could detect two premutation carriers in the POI group (1.6\%) and one in the control group (0.9\%). No premutation carriers were identified in the DOR group. The frequency of FMR1 premutations was not different between POI or DOR and controls. The most common CGG repeat was 29 and 30, and the repeat length for allele 2 had a secondary peak around 36-39 repeats. The CGG repeats were divided into groups of five consecutive values, and the distribution of allele 1 in the POI group was different from that in the control group $(P<0.001)$. No statistically significant differences were found for allele 1 between DOR group vs. controls, and for allele 2 between three groups $(P>0.05)$.

Conclusions: The study shows that the frequency of FMR1 premutations is relatively low (1.6\%) in Chinese women with POI. The distribution of allele 1 CGG repeat in patients with POI showed difference from that in healthy women.

Keywords: Premature ovarian insufficiency, Diminished ovarian reserve, Premutations, FMR1 alleles, Chinese population

\footnotetext{
* Correspondence: yuqi2008001@sina.com

Department of Obstetrics and Gynecology, Peking Union Medical College Hospital, Peking Union Medical College, Chinese Academy of Medical Science, No 1 Shuaifuyuan, Wangfujing, Beijing 100730, DongCheng District, China
}

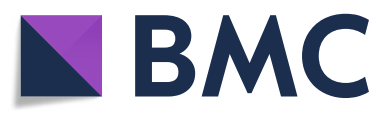

(c) The Author(s). 2020 Open Access This article is licensed under a Creative Commons Attribution 4.0 International License, which permits use, sharing, adaptation, distribution and reproduction in any medium or format, as long as you give appropriate credit to the original author(s) and the source, provide a link to the Creative Commons licence, and indicate if changes were made. The images or other third party material in this article are included in the article's Creative Commons licence, unless indicated otherwise in a credit line to the material. If material is not included in the article's Creative Commons licence and your intended use is not permitted by statutory regulation or exceeds the permitted use, you will need to obtain permission directly from the copyright holder. To view a copy of this licence, visit http://creativecommons.org/licenses/by/4.0/ The Creative Commons Public Domain Dedication waiver (http://creativecommons.org/publicdomain/zero/1.0/) applies to the data made available in this article, unless otherwise stated in a credit line to the data. 


\section{Introduction}

The fragile $\mathrm{X}$ mental retardation 1 (FMR1) gene, located at Xq27.3, is an X-linked gene, carrying CGG repeats in the $5^{\prime}$-untranslated region. Based on the criteria stated by the American College of Medical Genetics and Genomics (ACMG), FMR1 CGG repeats can be classified as normal ( $<45$ repeats), intermediate ( $45-54$ repeats), premutation (55-199 repeats), and full mutation ( $>200$ repeats) [1].

The ovarian reserve indicates a woman's reproductive potential, which is a function of the number and quality of oocytes [2]. Premature ovarian insufficiency (POI) is a condition that accentuates the extreme spectrum of impaired ovarian function. It is characterized by failure of ovarian function in women less than 40 years of age [3]. The decline of ovarian reserve is a continuous, gradual process and the concept of decreased or diminished ovarian reserve (DOR) has been explored in few reports earlier [4]. DOR is not an overt phenotype and was once described as 'occult POI' [5]. Compared with women of similar age, women with DOR commonly have regular menses but they also have reduced number of ovarian follicles and reduced fecundity [2]. It is thought that DOR may or may not progress into POI eventually (depending on whether amenorrhea occurs before the age of 40 years).

Numerous studies have examined the association between FMR1 CGG repeats and ovarian dysfunction [69]. In western countries, premutation of FMR1 are reportedly correlated with POI in women [7-9], which is now referred to as fragile- $\mathrm{X}$-associated primary ovarian insufficiency (FXPOI). It has been estimated that around $11-14 \%$ of familial and $2-6 \%$ of sporadic POI cases are associated with FMR1 premutations [3]. Association between normal or intermediate range FMR1 alleles and a reproductive risk has also been explored [10, 11]. Multiple association studies of FMR1 alleles, i.e. CGG repeats > 36 [12], 41-58 [13], 45-54 [9], and 35-54 [14] have been reported to be associated with POI. However, the distribution of FMR1 CGG repeats also varies with ethnicity [15]. Fewer patients with POI from Asia carried the FMR1 premutations [16].

The pathogenic role of $F M R 1$ premutations in Chinese women is controversial. Three earlier studies have shown very low prevalence of premutation carriers in Chinese women with POI $(<1 \%)[17-19]$, which is lower than studies from western countries [3]. Therefore, FMR1 premutation may not be a common explanation for POI in Chinese women.

With regard to the relationship between DOR and FMR1, the results are inconsistent: Women with DOR might be at a risk of carrying alleles in the premutation range $[5,20]$. Some studies found an association between DOR and normal/intermediate CGG repeats, including
$<26$ [21], <28 [22], 35-54 [23], 45-54 [9, 24], or $>40$ [5] and have reported a negative effect on ovarian ageing. By contrast, some studies reported that ovarian reserve was not affected by CGG repeats [23-27]. The role of FMR1 in Chinese women with DOR has not been extensively investigated.

The present study assessed the distribution of the FMR1 CGG repeat numbers in Chinese women with POI, DOR and compare it to the control group of natural menopausal women. The primary aim of this study is to establish whether CGG repeats are different in the Chinese population of POI and DOR within normal women. The association between the numbers of CGG repeats and endocrine profiles of these patients was also evaluated.

\section{Methods}

This study protocol was approved by the Institutional Review Board (IRB) of Peking Union Medical College Hospital (PUMCH) (No. JS-1604).

\section{Study participants}

One hundred twenty-four women with POI and 57 women with DOR were included in this cross-sectional case-control study. All women were clinically diagnosed with POI or DOR between May 2018 and December 2019 in the Department of Gynecological Endocrinology and Reproductive Medicine of PUMCH. The inclusion criteria for POI group were: amenorrhea ( $\geq 6$ months) before the age of 40 years and elevated serum folliclestimulating hormone (FSH) levels (> $25 \mathrm{IU} / \mathrm{L})$. The inclusion criteria for DOR group: having regular or irregular menstrual cycles, FSH $>10 \mathrm{IU} / \mathrm{L}$ on days $2-4$ of menstrual cycle and/or anti-mullerian hormone (AMH) levels $\leq 1.1 \mathrm{ng} / \mathrm{ml}$ on any day [28] before the age of 40 years. All women had normal karyotype and had no family history of fragile X syndrome (FXS). Women who had a history of autoimmune disease, pelvic surgery or chemo/radiotherapy were excluded.

After obtaining written informed consent, blood samples were obtained from each participant for both phenotypic and genotypic analysis. The blood samples from women with regular menstruation were collected during the early follicular phase for measurements of sex hormones. There was no restriction on the day of blood collection for women with amenorrhea. The serum estradiol $\left(\mathrm{E}_{2}\right)$ and FSH were measured at PUMCH Clinical laboratory using a chemiluminescence immunoassay (Roche ${ }^{\circ}$, Switzerland) and AMH was measured using an electro-chemiluminescent assay (Roche ${ }^{\circledR}$, Switzerland). A detailed clinical questionnaire was filled for each subject, which included details like menstrual and reproductive history along with personal and family history. 
The control group included 111 post-menopausal women. The comparison data is from the PUMCH Aging Longitudinal Cohort of Midlife Women (PALM), a prospective, open-cohort, which involved with a community-based longitudinal study, aiming to investigate ovarian ageing in midlife women in China [29]. The participants were middle-aged female residents of the TieEr community, Xicheng District, Beijing, China. The inclusion criteria were women who had undergone natural menopause after the age of 40 years, no history of severe systemic diseases, no use of hormonal medications in the previous 3 months, no history of any gynecological endocrine diseases, and not pregnant or lactating in the previous 6 months. An additional blood sample was obtained from each participant for FMR1 analysis during the follow up in 2018.

\section{FMR1 assay measures}

Genomic DNA was extracted from peripheral blood leukocytes of all participants using standard procedures using commercial DNA extraction kits (Tiangen, Beijing, China). The FMR1 repeat region was amplified by polymerase chain reaction (PCR) using the FragilEase PCR reagent kit (PerkinElmer, USA) following manufacturer's protocol. Following primers were used: forward (TCAG GCGCTCAGCTCCGTTTCGGTTTCA), reverse (FAMAAGCGCCATTGGAGCCCCGCACTTCC). Two female reference DNA samples (30/80 repeats and 20/200 repeats) were obtained from the Coriell Institute for Medical Research (Camden, US) to evaluate the analytical performance of the assay. The reference samples were concurrently amplified. All PCR products were purified using the PureLink PCR Micro Kit (Invitrogen) prior to electrophoresis. And a microfluidic capillary electrophoresis instrument (LabChip ${ }^{\oplus}$ MultiDX) was used to estimate allele sizing. Calculation of the CGG repeat lengths was performed using FraXsoft analysis software (PerkinElmer, USA) by utilizing base pair size data. An analytical and clinical validation of this kit has been performed previously, which proved that the CGG repeats obtained using this assay are highly concordant with those obtained using the conventional reference method (PCR + Southern blot) for 112 archived samples, including 25 samples with a full mutation (the largest allele repeat was 1380 repeats) [30]. The intra-assay (coefficient of variation $<2.5 \%$ ) and inter-assay imprecision was within 1 repeat.

\section{Statistical analysis}

The FMR1 analysis in women provides two numbers of the CGG repeat length on two X chromosomes. Consistent with the methodologies used in earlier studies [15, 31 , the allele with the smaller number of CGG repeats was termed "allele 1", and the allele with the larger number of CGG repeats was termed "allele 2". Continuous variables with normal distributions were expressed as mean \pm standard deviation (SD). Categorical variables are presented as numbers (percentages). Discrete categories for CGG repeat categories were presented per 5 repeat lengths. The categorical distributions of allele 1 and allele 2 CGG repeat lengths were compared among different groups. Comparisons of categorical allele variables were made using the non-parametric MannWhitney test. Association analysis of continuous variables was used t-testing (two groups) or ANOVA (three or more groups).

Since some studies have shown 25-34 repeats as "normal" [21], a comparison of the proportion of alleles 1 and 2 was made with $<25,25-34$, and $>34$ repeats between the POI or DOR group and the controls. A study which included primarily the Caucasian race (76\%) and $11 \%$ of Asian race have compared the infertile women with DOR with the general female population, and found that the DOR group was more likely to have 35-44 CGG repeats (14.5\% vs. 3.9\%) [23]. Therefore, comparisons were also made between different groups with respect to 35-44 CGG repeats. Previous reports also showed the onset of amenorrhea occurred significantly earlier in the patients with $>38$ CGG repeats [12]. The comparison of menopausal age between women having allele 2 with $\leq 38$ repeats and $>38$ repeats was done using Fisher's exact test with alpha $<0.05$.

All analyses were performed using SPSS software (version 24.0 for the OS X system; IBM). All the tests were two-sided with 0.05 significance level.

\section{Results}

Baseline characteristics

We estimated the CGG repeat numbers in the FMR1 gene of 124 patients with POI, 57 women with DOR, and 111 controls. Table 1 shows the characteristics of the three groups. Eight of the 124 women with POI were primary amenorrhea, whereas 116 women were secondary amenorrhea, and the mean \pm SD of menopausal age was $28.4 \pm 7.1$ years. In the DOR group, more than half the women (50.9\%) had FSH values between 10 and 15 IU/L, 29.8\% had FSH between 15.1 and $20.0 \mathrm{IU} / \mathrm{L}$, and $12.3 \%$ had FSH > $20 \mathrm{IU} / \mathrm{L}$. About $7.0 \%$ of women with DOR had FSH values lower than $10 \mathrm{IU} / \mathrm{L}$, but had AMH values lower than $1.1 \mathrm{ng} / \mathrm{ml}$. Forty-one (71.9\%) women had both increased FSH and reduced AMH values.

\section{FMR1 CGG repeat distribution}

The FMR1 CGG repeat distribution in POI, DOR, and control groups is shown in Fig. 1a (allele 1) and Fig. 1b (allele 2). The overall pattern of distribution in different groups is almost similar. The most common CGG repeat of both alleles in all the groups was 29 and 30. The 
Table 1 Characteristics of patients with POI, DOR and control women

\begin{tabular}{|c|c|c|c|c|c|c|}
\hline Parameter & $\mathrm{POI}$ & DOR & Control $^{\mathbf{b}}$ & $P_{1}^{a}$ & $P_{2}{ }^{a}$ & $P_{3}{ }^{a}$ \\
\hline $\mathbf{N}$ & 124 & 57 & 111 & & & \\
\hline Enrolled age, yrs, mean \pm SD & $31.3 \pm 6.5$ & $32.5 \pm 3.8$ & $48.0 \pm 6.1$ & $<0.001$ & $<0.001$ & 0.149 \\
\hline Age at menarche, yrs, mean $\pm S D$ & $13.4 \pm 1.6$ & $13.2 \pm 1.2$ & & & & 0.395 \\
\hline Age at menopause, yrs, mean \pm SD & $28.4 \pm 7.1$ & NA & $50.7 \pm 3.0$ & $<0.001$ & & \\
\hline BMI $\left(\mathrm{kg} / \mathrm{m}^{2}\right)$, mean $\pm S D$ & $22.1 \pm 3.8$ & $21.6 \pm 3.5$ & $25.0 \pm 3.2$ & $<0.001$ & $<0.001$ & 0.351 \\
\hline Currently Smoking, No. (\%) & $3(2.7)$ & $1(1.8)$ & $2(1.8)$ & 0.307 & 0.565 & 0.593 \\
\hline $\mathrm{FSH}(\mathrm{IU} / \mathrm{l})$, mean $\pm \mathrm{SD}$ & $81.7 \pm 35.8$ & $15.0 \pm 4.8$ & $30.5 \pm 30.8$ & $<0.001$ & $<0.001$ & $<0.001$ \\
\hline Estradiol $(\mathrm{pg} / \mathrm{ml})$, mean \pm SD & $33.3 \pm 38.4$ & $46.4 \pm 27.6$ & $87.7 \pm 125.1$ & $<0.001$ & 0.001 & 0.027 \\
\hline $\mathrm{AMH}(\mathrm{ng} / \mathrm{ml})$, mean $\pm \mathrm{SD}$ & $0.06 \pm 0.18$ & $0.80 \pm 0.76$ & & & & $<0.001$ \\
\hline FMR1 Allele1, mean \pm SD & $29.8 \pm 2.1$ & $29.3 \pm 3.5$ & $29.9 \pm 3.8$ & 0.694 & 0.281 & 0.330 \\
\hline Median [IQR] & $29[29,30]$ & $30[29,31]$ & $30[29,31]$ & & & \\
\hline FMR1 Allele2, mean \pm SD & $33.4 \pm 7.7$ & $32.2 \pm 4.1$ & $33.2 \pm 5.0$ & 0.847 & 0.202 & 0.290 \\
\hline Median [IQR] & $30[30,36]$ & $31[30,34.5]$ & $31[30,37]$ & & & \\
\hline
\end{tabular}

${ }^{a} P_{1}$ indicated $P O I$ versus controls, $P_{2}$ indicated DOR versus controls, and $P_{3}$ indicated $P O I$ versus DOR

b the characteristics presented in the Table were results at baseline assessment of the women in the control group

Abbreviation: POI Premature ovarian insufficiency, DOR Diminished ovarian reserve, FSH Follicle-stimulating hormone, $A M H$ Anti-mullerian hormone, SD Standard

deviation, $B M I$ Body mass index, IQR Interquartile range, NA Not applicable

distribution of alleles among groups were compared, and no significant difference was found.

Screening of the FMR1 gene identified 2 premutation carriers with repeats $31 / 56,30 / 98$ in the POI group $(1.6 \%)$, and 1 with repeats $40 / 59$ in the control group $(0.9 \%)$. Four intermediate repeat carriers were found: 1 in the POI group $(0.8 \%), 1$ in the DOR group $(1.8 \%)$ and 2 in controls $(1.8 \%)$. No full mutation subtype was found in all groups. For allele 1, there were no intermediate or premutation carriers. The repeat lengths for allele 2 were in the range of 26-98 in all the participants, and had a secondary peak around 36-39 repeats. Homozygous CGG repeat lengths were common in both the groups (POI group: 50.0\%; DOR group: 61.4\%; control group: $66.7 \%$ ), and the commonest repeats were $30 / 30$ and $29 /$ 29 repeats in all the groups.

\section{Distribution of CGG repeats in POI, DOI, and controls}

The CGG repeats were also divided into groups of five consecutive values (Table 2). The distribution of allele 1 in the POI group was different from that in the control group $(P<0.001)$. No statistically significant differences were found for allele 1 between DOR group vs. controls, for allele 2 between POI group vs. controls, and DOR group vs. controls $(P>0.05)$. The proportion of $<25$, $25-34,35-44$ and $>44$ group for both the alleles are shown in Fig. 2. Comparing the distribution between the POI vs. controls and DOR vs. controls, the distribution of allele 1 was different between the POI group and the control group $(P=0.044)$, whereas there was no significant difference between the DOR group and controls for allele 1 , and for allele 2 between POI or DOR group and controls for allele $2(P>0.05)$.
The association between FMR1 CGG repeats and the age at menopause was explored in POI women (Table 2). Menopausal ages of women with different CGG repeats groups showed no statistically significant difference $(P>0.05)$. Furthermore, the mean FSH and AMH values did not show any association with different CGG repeats in both the POI and DOR groups (Table 2). Comparison of menopausal age between women having allele 2 with $\leq 38$ repeats $(n=100)$ and $>38$ repeats $(n=$ 16) revealed no significant difference $(28.1 \pm 7.3$ vs. $30.0 \pm 5.1, P=0.321)$.

\section{Discussion}

In the present study, we compared the distribution of FMR1 CGG repeats among 124 patients with POI, 57 patients with DOR and 111 controls in Chinese population. No statistically significant differences were identified between the DOR group and the control group, whereas the distribution of allele 1 CGG repeat in patients with POI was difference from that in the control group. Frequency of premutation was relatively low in both healthy women and patients with ovarian dysfunction in China: two cases with premutation carriers were identified in the POI group, 1 premutation carrier in the control group, and no carriers were found in the DOR group.

POI occurs in $1 \%$ of women and has severe consequences, including infertility and chronic hypoestrogenism that may result in increased cardiovascular risk, impaired bone health, and considerable psychosocial sequelae [32]. A higher prevalence of spontaneous POI has been reported from a very recent meta-analysis, i.e. 3.7\% among all women worldwide [33]. Hormone replacement therapy, the principal therapeutic approach for POI, helps alleviate 


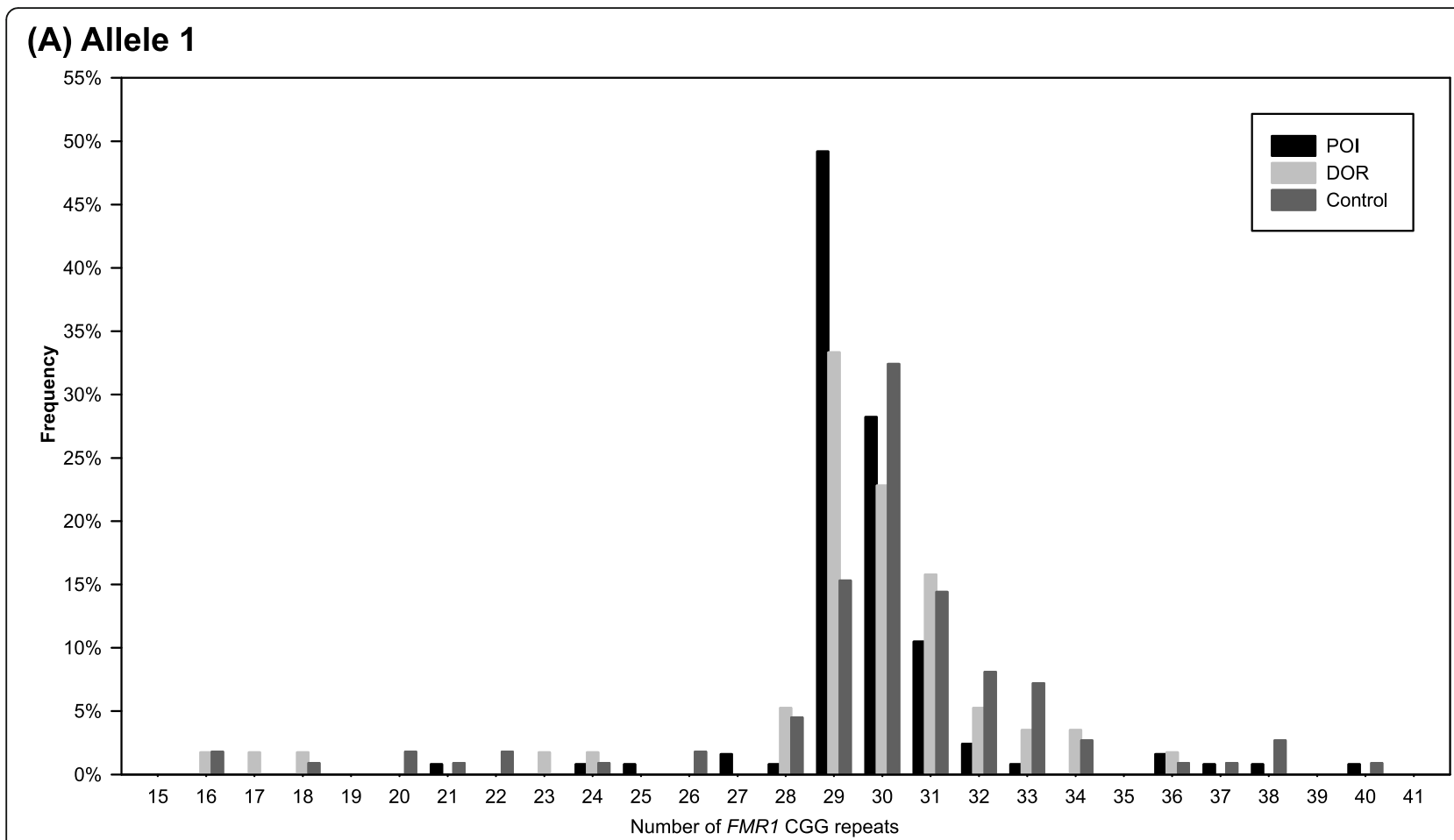

(B) Allele 2

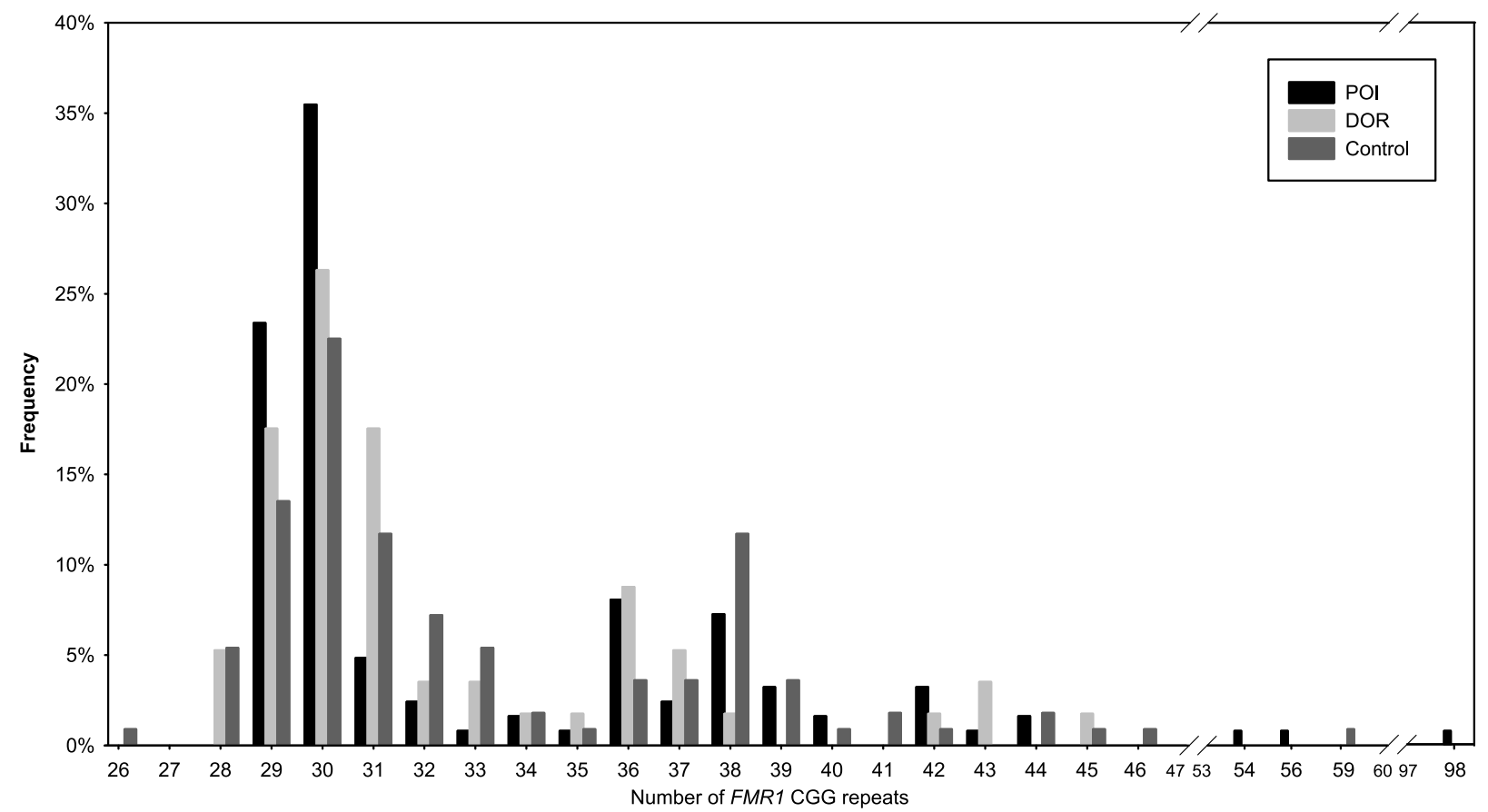

Fig. 1 Distribution of FMR1 CGG repeat numbers in Chinese patients with POI, DOR and controls. a, b Data from allele 1 (a) and allele 2 (b) $(N=124,57$ and 111 for patients with POI, DOR and controls, respectively). Abbreviations: FMR1, the fragile X mental retardation 1; POI primary ovarian insufficiency; DOR diminished ovarian reserve

the related symptoms although this does not effectively solve the issues related to fertility.

The main cause of POI is unknown, but genetic factors, autoimmune ovarian damage, iatrogenic and environmental factors are the known causes. Among all the genetic factors implicated for POI, the FMR1 premutation is regarded as the leading single-gene cause of POI [34]. If FMR1 screening for the target population 
Table 2 Detailed distribution by 5 CGG repeat bands up through the premutation in patients with POI, DOR and controls

\begin{tabular}{|c|c|c|c|c|c|c|c|c|}
\hline FMR1 CGG Repeats & $\mathrm{N}$ & $<25$ & $25-29$ & $30-34$ & $35-39$ & $40-44$ & 45-54 (Intermediate) & 55-199 (Premutation) \\
\hline \multicolumn{9}{|l|}{ Allele1 } \\
\hline POI group, N (\%) & 124 & $2(1.6)$ & $65(52.4)$ & $52(41.9)$ & $4(3.2)$ & $1(0.8)$ & 0 & 0 \\
\hline $\begin{array}{l}\text { Age at menopause, yrs., } \\
\text { mean (SD) }\end{array}$ & & $16.5(2.1)$ & $28.9(7.3)$ & $28.7(6.5)$ & $23.5(6)$ & 22 & & \\
\hline FSH (IU/I), mean (SD) & & $95.2(43.3)$ & $79(36.2)$ & $81.4(38.5)$ & $67.5(34.9)$ & 129.3 & & \\
\hline AMH $(n g / m l)$, mean (SD) & & 0 & $0.1(0.3)$ & $0(0.1)$ & 0 & 0 & & \\
\hline DOR group, N (\%) & 57 & $5(8.8)$ & $22(38.6)$ & $29(50.9)$ & $1(1.8)$ & 0 & 0 & 0 \\
\hline FSH (IU/I), mean (SD) & & $17.8(8.8)$ & $15.5(4.7)$ & $14.1(3.9)$ & 16.9 & & & \\
\hline AMH $(n g / m l)$, mean (SD) & & $1.0(0.9)$ & $0.7(0.6)$ & $0.8(0.8)$ & 0.9 & & & \\
\hline Control group, N (\%) & 111 & $9(8.1)$ & $24(21.6)$ & $72(64.9)$ & $5(4.5)$ & $1(0.9)$ & 0 & 0 \\
\hline $\begin{array}{l}\text { Age at menopause, yrs., } \\
\text { mean (SD) }\end{array}$ & & $52(2)$ & $50.5(3.3)$ & $50.5(2.9)$ & $52.8(4)$ & 51.0 & & \\
\hline FSH (IU/I), mean (SD) & & $27.3(29.5)$ & $26.9(26.9)$ & $32.5(32.7)$ & $21.8(29.6)$ & 52.9 & & \\
\hline \multicolumn{9}{|l|}{ Allele2 } \\
\hline POI group, N (\%) & 124 & 0 & $29(23.4)$ & $56(45.2)$ & $27(21.8)$ & $9(7.3)$ & $1(0.8)$ & $2(1.6)$ \\
\hline $\begin{array}{l}\text { Age at menopause, yrs., } \\
\text { mean (SD) }\end{array}$ & & & $29.6(6.7)$ & $27.9(7.4)$ & $27.6(7.5)$ & $27.8(5.5)$ & 30.0 & $35.5(2.1)$ \\
\hline FSH (IU/I), mean (SD) & & & $87.2(36.8)$ & $80.8(39.5)$ & $76.5(36.2)$ & $70.2(29.6)$ & 110.5 & $59.1(10.3)$ \\
\hline AMH (ng/ml), mean (SD) & & & 0.0 & $0.1(0.3)$ & 0.0 & 0.0 & 0.0 & $0.1(0.2)$ \\
\hline DOR group, N (\%) & 57 & 0 & $13(22.8)$ & $30(52.6)$ & $10(17.5)$ & $3(5.3)$ & $1(1.8)$ & 0 \\
\hline FSH (IU/I), mean (SD) & & & $15.9(4.7)$ & $14.4(5.3)$ & $15.3(3.8)$ & $17.4(1.5)$ & 11.0 & \\
\hline AMH (ng/ml), mean (SD) & & & $0.5(0.6)$ & $0.9(0.9)$ & $0.9(0.6)$ & $0.4(0.3)$ & 0.7 & \\
\hline Control group, N (\%) & 111 & 0 & $22(19.8)$ & $54(48.6)$ & $26(23.4)$ & $6(5.4)$ & $2(1.8)$ & $1(0.9)$ \\
\hline $\begin{array}{l}\text { Age at menopause, yrs., } \\
\text { mean (SD) }\end{array}$ & & & $51.3(3)$ & $50.5(3.1)$ & 50.9 (3) & $51(1.9)$ & $46.5(2.1)$ & 51.0 \\
\hline FSH (IU/I), mean (SD) & & & $23.6(25.3)$ & $28.8(30.7)$ & $39.3(34.5)$ & $15.2(18.8)$ & $68.9(32.3)$ & 52.9 \\
\hline
\end{tabular}

Fisher's exact tests for allele 1: comparison by POI versus control $(P<0.001)$; comparison by DOR versus control $(P=0.148)$. Fisher's exact tests for allele 2: comparison by $\mathrm{POI}$ versus control $(P=0.903)$; comparison by DOR versus control $(P=0.884)$. The menopausal ages, values of FSH and AMH of women with different CGG repeats groups showed no statistically significant difference $(P>0.05)$

Abbreviation: POI Primary ovarian insufficiency, DOR Diminished ovarian reserve, FSH Follicle-stimulating hormone, $A M H$ Anti-mullerian hormone

could select women with high risk of POI, it has longterm benefits to family and enables them in planning the families with an opportunity to adopt alternate methods. The American College of Obstetricians and Gynecologists (ACOG) and the European Society of Human Reproduction and Embryology (ESHRE) recommend population-based FMR1 screening for women younger than 40 years of age and presenting with ovarian insufficiency $[35,36]$. FMR1 testing has a dual role in patients with ovarian insufficiency: determining the probable cause of ovarian failure and identifying women at risk of transmitting mutations to their offspring. However, studies have shown wide heterogeneity and inconsistency in the association between FMR1 CGG repeats and POI susceptibility across different ethnicities [15, 37].

FMR1 premutation carriers showed an increased risk of POI, especially in a population of European descent [37]. However, this factor may not contribute to the POI susceptibility in the Asian population [37, 38]. Studies of
Iranian [39] and Indian [37] populations found no significant relationship between the FMR1 CGG repeat and POI. Studies from China also showed FMR1 premutation to be an uncommon explanation for POI $[18,19]$. The frequency of premutation carriers among Chinese women with sporadic POI ranges between 0.5 and $0.9 \%$ in three previous studies [17-19]; these studies analyzed FMR1 CGG repeats using PCR and capillary electrophoresis. Our study shows the premutation frequency in the POI group was $1.6 \%$ using PCR and microfluidic capillary electrophoresis. A previous study showed that the repeat sizes determined from both methods were largely concordant and, on average, were within one repeat size difference [30]. Then, we speculated that the error rate within the two methods is acceptable. Our results combined with three previous reports in China, shows the premutation frequency in Chinese women with sporadic POI may be $0.87 \%$ (6/693). Typically, in healthy women, the premutation carrier frequency has been reported as 


\section{(A) Allele 1}

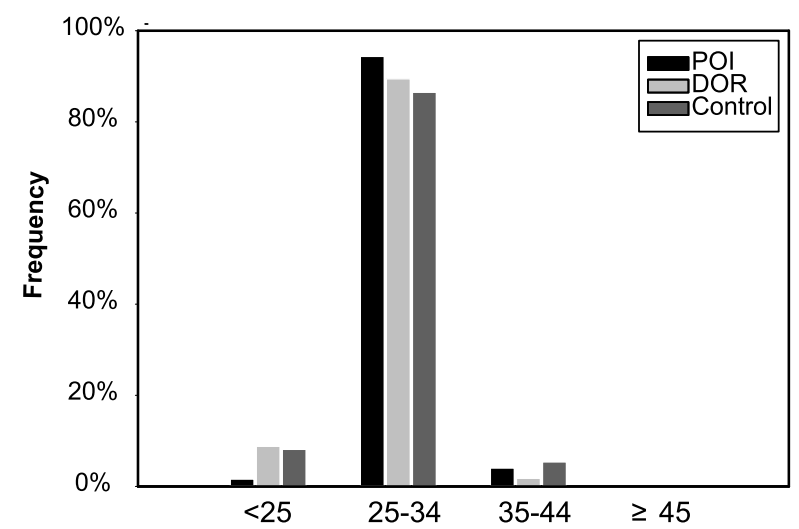

(B) Allele 2

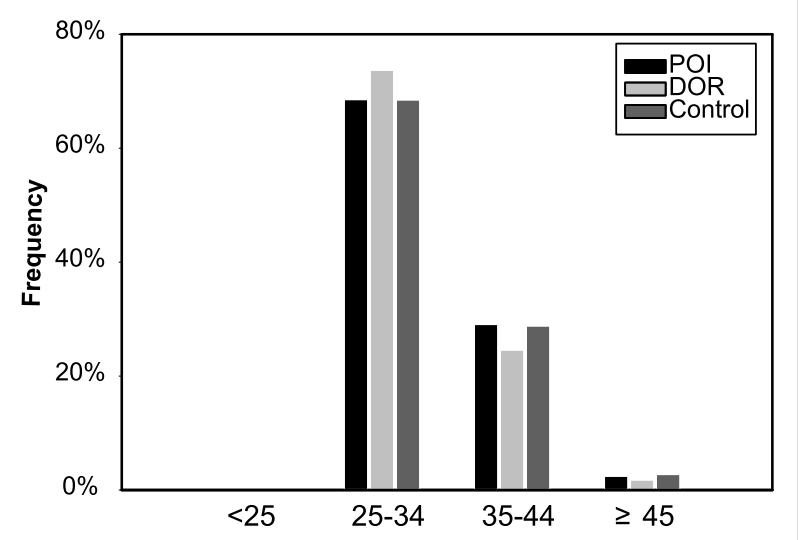

Fig. 2 Frequency distribution of CGG repeats in POI, DOR cases and controls in groups $<25,25-34,35-44$, and $\geq 45$. Abbreviations: POI primary ovarian insufficiency; DOR diminished ovarian reserve

1/579-1/1955 in China [40-42], 1/781 in Korea [43]. The permutation frequency in Asian women [41] is much lower than the statistics in white (1/169), African American (1/124), and Hispanic (1/287) healthy women [44]. Although limited by sample size, our study found no statistical difference in the premutation carrier frequency among POI and healthy women. It is possible that the premutation carrier frequency in Chinese POI patients is higher than that in healthy women, but the overall incidence is relatively low in both groups. Further study with a larger sample size is needed to get a definite conclusion.

Studies have reported controversial outcomes, wherein intermediate and normal alleles are associated with POI frequency [13, 14, 19]. Our study, in agreement with others, found the distribution of allele 1 in the POI group was different from healthy women. Another study from China suggested that the CGG repeats in allele 1, and not allele 2, were significantly associated with POI occurrence [17]. The risk of POI occurrence for $<26$ and $\geq 29$ CGG repeats in allele 1 was higher than that for 26-28 CGG repeats. Gleicher et al. [45] demonstrated that $<26$ repeats of both alleles have negative effects on reproduction.

Various studies also explored the association of FMR1 CGG repeats with DOR. Most of these studies have shown association of DOR with the number of CGG repeats of the FMR1 gene [5, 9, 21-24, 46], while few other studies including ours suggest that the number of CGG repeats of the FMR1 gene seems to be independent of DOR [26, 27]. Our study found no difference in the CGG repeats of allele 1 between the DOR and control groups in Chinese women. Pastore et al. [25] found a significant difference in the CGG repeats of allele 1 between the DOR cases and women with a normal reproductive history among the Whites, but not the Asians, since Asian women seem less likely to have an allele with $\leq 25$ CGG repeats than other races [25, 47]. Race variation may be associated with the different results.

The previously reported frequency of 35-44 repeats is $14.5-17 \%$ in the DOR group and $3.9 \%$ in the controls [5, 23], suggesting that the CGG repeats of 35-44 may be markedly overrepresented in women with DOR. We compared the proportion of 35-44 CGG repeats among groups in this study, and found no difference of the prevalence between the DOR group and control. In the control group, which included women with normal menopausal age, the frequency of 35-44 CGG repeats is $28.8 \%$, which is much higher than in previous reports. The difference might be attributable to the presence of the secondary modal peak seen in the Asian population. Women in the present study had a primary modal peak at 29 to 31 repeats and a secondary modal peak at 36 to 38 repeats of allele 2. Reports showed other Asians such as Japanese [12, 48] and Indonesians [41] also have a secondary peak, which was not identified in studies of western populations [12]. The presence of a secondary modal peak may be related to varied outcomes across different races.

The underlying mechanism behind CGG repeats regulating FMR1 gene expression in the ovary, and thereby affecting ovarian function remains unknown. It is unclear whether the reduced ovarian reserve represents a pathological condition resulting from abnormally accelerated atresia in a normal antral follicular pool or an abnormally small initial pool of oocytes [49]. A recent study showed that various CGG expansions of an FMR1 allele may lead to changes in RNA level and ratios of distinct RNA isoforms, which could regulate the translation and/or cellular localization of fragile $\mathrm{X}$ mental retardation protein (FMRP), affecting the expression of steroidogenic enzymes and hormonal receptors, that 
result in ovarian dysfunction [50]. In addition, Dioguardi et al. found that the permutation transcript contributes to the mitochondrial and ovarian abnormalities in permutation mouse models [51]. Studies showed that ovaries from Fmr1 knockout mice show increased mTOR protein $[52,53]$, and the YAC mice with premutation CGG repeat show reduced phosphorylated mTOR levels [54]. Then, both underexpression and overexpression of mTOR can result in ovarian dysfunction [55]. A recent study showed a potential relationship between the regulation of FMR1/FMRP expression and the AKT/mTOR signaling pathway in a human proliferating granulosa cell model system [56]. The above experiments suggest the mTOR pathway as a potential therapeutic target. However, the result of CGG repeats affecting the ovarian ageing process in various ethnicities is inconsistent, and the mechanism of heterogeneity in varied ethnicity is unclear. Further functional studies are needed to explain the inconsistent results across different ethnicities and susceptibility to ovarian insufficiency.

The primary strength of this study was the identification of women with a well-defined phenotype, independent of any potential risk factors for analysis of FMR1 CGG repeats. Second, as the association FMR1 gene and DOR has not been evaluated, by enrolling both POI and DOR patients in this study, we could have a comparison between these two groups in one Center. The primary limitation of the study however is the relatively small sample size.

\section{Conclusions}

No difference of FMR1 alleles in the premutation ranges were found between POI or DOR and healthy women and the frequency of premutation was relatively low in Chinese women. The distribution of allele 1 CGG repeat in patients with POI showed some different from that in healthy women. Although FMR1 testing has been recommended in the evaluation of the etiology of ovarian insufficiency in western countries, screening for the same among Chinese women is not warranted as the low frequency of occurrence. Further investigations with larger sample sizes is necessary to study the incidence of FMR1 expansions in all forms of ovarian insufficiency to confirm the results of this pilot study.

\section{Acknowledgements}

The authors are deeply grateful to all participants involved in this study and all the doctors and researchers who participated in the study.

\section{Authors' contributions}

Material preparation, data collection and analysis were performed by R. T and $\mathrm{Q}$. Y. The first draft of the manuscript was written by R. T. and Q. Y. commented on previous versions of the manuscript. The authors read and approved the final manuscript.

\section{Funding}

This study was supported by the National Key Research and Development Program [grant number 2018YFC1002105]; CAMS Innovation Fund for Medical Sciences (CIFMS) [grant number 2017-I2M-1-002]; and the Wu Jieping Medical Foundation Clinical Research Project [grant number 320.6750.16183].

\section{Availability of data and materials}

The datasets used and/or analysed during the current study are available from the corresponding author on reasonable request.

\section{Ethics approval and consent to participate}

All procedures performed in studies involving human participants were in accordance with the ethical standards of the institutional research committee of Peking Union Medical College Hospital (No. JS-1604). Informed consent was obtained in accordance with the institutional guidelines.

\section{Consent for publication}

All the patients signed a consent form prior recruited for this study.

\section{Competing interests}

The authors declare that they have no competing interests.

Received: 13 May 2020 Accepted: 10 August 2020

Published online: 12 August 2020

\section{References}

1. Monaghan K, Lyon E, Spector E. ACMG standards and guidelines for fragile $X$ testing: a revision to the disease-specific supplements to the standards and guidelines for clinical genetics Laboratories of the American College of medical genetics and genomics. Genet Med. 2013;15(7):575-86. https://doi. org/10.1038/gim.2013.61.

2. Medicine ASfR. Testing and interpreting measures of ovarian reserve: a committee opinion. Fertil Steril. 2015;103(3):e9-e17. https://doi.org/10.1016/ j.fertnstert.2014.12.093.

3. Man L, Lekovich J, Rosenwaks Z, Gerhardt J. Fragile X-associated diminished ovarian reserve and primary ovarian insufficiency from molecular mechanisms to clinical manifestations. Front Mol Neurosci. 2017;10:290. https://doi.org/10.3389/fnmol.2017.00290.

4. Cohen J, Chabbert-Buffet N, Darai E. Diminished ovarian reserve, premature ovarian failure, poor ovarian responder--a plea for universal definitions. J Assist Reprod Genet. 2015;32(12):1709-12. https://doi.org/10.1007/s10815015-0595-y.

5. Streuli I, Fraisse T, Ibecheole V, Moix I, Morris MA, de Ziegler D. Intermediate and premutation FMR1 alleles in women with occult primary ovarian insufficiency. Fertil Steril. 2009;92(2):464-70. https://doi.org/10.1016/j. fertnstert.2008.07.007.

6. Sullivan AK, Marcus M, Epstein MP, Allen EG, Anido AE, Paquin JJ, et al. Association of FMR1 repeat size with ovarian dysfunction. Hum Reprod. 2005;20(2):402-12. https://doi.org/10.1093/humrep/deh635.

7. Pelosi E, Simonsick E, Forabosco A, Garcia-Ortiz JE, Schlessinger D. Dynamics of the Ovarian Reserve and Impact of Genetic and Epidemiological Factors on Age of Menopause1. Biol Reprod. 2015;92(5). https://doi.org/10.1095/ biolreprod.114.127381

8. Murray A, Schoemaker M, Bennett C, Ennis S, Macpherson J, Jones M, et al. Population-based estimates of the prevalence of FMR1 expansion mutations in women with early menopause and primary ovarian insufficiency. Genet Med. 2014;16(1):19-24.

9. Karimov C, Moragianni V, Cronister A, Srouji S, Petrozza J, Racowsky C, et al. Increased frequency of occult fragile $X$-associated primary ovarian insufficiency in infertile women with evidence of impaired ovarian function. Hum Reprod. 2011;26(8):2077-83.

10. Bennett C, Conway G, Macpherson J, Jacobs P, Murray A. Intermediate sized CGG repeats are not a common cause of idiopathic premature ovarian failure. Hum Reprod. 2010;25(5):1335-8.

11. Spath MA, Feuth TB, Smits AP, Yntema HG, Braat DD, Thomas CM, et al. Predictors and risk model development for menopausal age in fragile $X$ premutation carriers. Genet Med. 2011;13(7):643-50. https://doi.org/10.1097/ GIM.0b013e31821705e5.

12. Ishizuka B, Okamoto N, Hamada N, Sugishita Y, Saito J, Takahashi N, et al. Number of CGG repeats in the FMR1 gene of Japanese patients with 
primary ovarian insufficiency. Fertil Steril. 2011;96(5):1170-4. https://doi.org/ 10.1016/j.fertnstert.2011.08.028.

13. Bodega B, Bione S, Dalprà L, Toniolo D, Ornaghi F, Vegetti W, et al. Influence of intermediate and uninterrupted FMR1 CGG expansions in premature ovarian failure manifestation. Hum Reprod. 2006;21(4):952-7.

14. Bretherick KL, Fluker MR, Robinson WP. FMR1 repeat sizes in the gray zone and high end of the normal range are associated with premature ovarian failure. Hum Genet. 2005;117(4):376-82. https://doi.org/10.1007/s00439-0051326-8.

15. Pastore L, Manichaikul A, Wang X, Finkelstein J. FMR1 CGG repeats: reference levels and race-ethnic variation in women with Normal fertility (study of Women's health across the nation). Reprod Sci. 2016;23(9):1225-33.

16. Genereux DP, Laird CD. Why do fragile $X$ carrier frequencies differ between Asian and non-Asian populations? Genes Genet Syst. 2013;88(3):211-24.

17. Lu CL, Li R, Chen XN, Xu YY, Yan LY, Yan J, et al. The 'normal' range of FMR1 triple CGG repeats may be associated with primary ovarian insufficiency in China. Reprod Biomed Online. 2017;34(2):175-80. https://doi.org/10.1016/j. rbmo.2016.11.001

18. Guo T, Qin Y, Jiao X, Li G, Simpson J, Chen Z. FMR1 premutation is an uncommon explanation for premature ovarian failure in Han Chinese. PLoS One. 2014;9(7):e103316.

19. Ye Y, Lan X, Cong J, Li N, Wu Y, Zhang M, et al. Analysis of CGG repeats in FMR1 in Chinese women with idiopathic premature ovarian failure. Reprod Biomed Online. 2014;29(3):382-7. https://doi.org/10.1016/j.rbmo.2014.05.004.

20. Eslami A, Farahmand K, Totonchi M, Madani T, Asadpour U, Zari Moradi S, et al. FMR1 premutation: not only important in premature ovarian failure but also in diminished ovarian reserve. Hum Fertil (Camb). 2017;20(2):120-5. https://doi.org/10.1080/14647273.2016.1255356.

21. Gleicher N, Weghofer A, Barad DH. Ovarian reserve determinations suggest new function of FMR1 (fragile X gene) in regulating ovarian ageing. Reprod Biomed Online. 2010;20(6):768-75. https://doi.org/10.1016/j.rbmo.2010.02.020.

22. Gleicher N, Weghofer A, Oktay K, Barad D. Relevance of triple CGG repeats in the FMR1 gene to ovarian reserve. Reprod Biomed Online. 2009;19(3): 385-90.

23. Pastore L, Young S, Baker V, Karns L, Williams C, Silverman L. Elevated prevalence of 35-44 FMR1 trinucleotide repeats in women with diminished ovarian reserve. Reprod Sci. 2012;19(11):1226-31.

24. Voorhuis M, Onland-Moret NC, Janse F, Ploos van Amstel HK, Goverde AJ, Lambalk CB, et al. The significance of fragile $X$ mental retardation gene 1 CGG repeat sizes in the normal and intermediate range in women with primary ovarian insufficiency. Hum Reprod. 2014;29(7):1585-93. https://doi. org/10.1093/humrep/deu095.

25. Pastore LM, Young SL, Manichaikul A, Baker VL, Wang XQ, Finkelstein JS. Distribution of the FMR1 gene in females by race/ethnicity: women with diminished ovarian reserve versus women with normal fertility (SWAN study). Fertil Steril. 2017;107(1):205-11.e1. https://doi.org/10.1016/j.fertnstert. 2016.09.032

26. Schufreider A, McQueen D, Lee S, Allon R, Uhler M, Davie J, et al. Diminished ovarian reserve is not observed in infertility patients with high normal CGG repeats on the fragile X mental retardation 1 (FMR1) gene. Hum Reprod. 2015;30(11):2686-92.

27. De Geyter C, M'Rabet N, De Geyter J, Zurcher S, Moffat R, Bosch N, et al. Similar prevalence of expanded CGG repeat lengths in the fragile $X$ mental retardation I gene among infertile women and among women with proven fertility: a prospective study. Genet Med. 2014;16(5):374-8. https://doi.org/10. 1038/gim.2013.146.

28. Ferraretti AP, La Marca A, Fauser BCJM, Tarlatzis B, Nargund G, Gianaroli L. ESHRE consensus on the definition of 'poor response' to ovarian stimulation for in vitro fertilization: the Bologna criteria. Hum Reprod. 2011;26(7):161624. https://doi.org/10.1093/humrep/der092.

29. Sun $X$, Luo M, Ma M, Tang R, Wang Y, Liu G, et al. Ovarian aging: an ongoing prospective community-based cohort study in middle-aged Chinese women. Climacteric. 2018;21(4):404-10. https://doi.org/10.1080/ 13697137.2018.1458833.

30. Kwok YK, Wong KM, Lo FM, Kong GWS, Moore JK, Wu S, et al. Validation of a robust PCR-based assay for quantifying fragile X CGG repeats. Clin Chim Acta. 2016;456:137-43. https://doi.org/10.1016/j.cca.2016.02.027.

31. Voorhuis M, Onland-Moret N, Fauser B, Ploos van Amstel H, van der Schouw Y, Broekmans F. The association of CGG repeats in the FMR1 gene and timing of natural menopause. Hum Reprod. 2013;28(2):496-501.
32. Coulam CB, Adamson SC, Annegers JF. Incidence of premature ovarian failure. Obstet Gynecol. 1986;67(4):604-6.

33. Golezar S, Ramezani Tehrani F, Khazaei S, Ebadi A, Keshavarz Z. The global prevalence of primary ovarian insufficiency and early menopause: a metaanalysis. Climacteric. 2019;22(4):403-11. https://doi.org/10.1080/13697137. 2019.1574738

34. Hoyos LR, Thakur M. Fragile X premutation in women: recognizing the health challenges beyond primary ovarian insufficiency. J Assist Reprod Genet. 2017;34(3):315-23. https://doi.org/10.1007/s10815-016-0854-6.

35. Genetics. ACoOaGCo. ACOG Committee Opinion No. 469: carrier screening for fragile X syndrome. Obstet Gynecol. 2010;116(4):1008-10. https://doi.org/ 10.1097/AOG.0b013e3181fae884.

36. Group TECW. Genetic aspects of female reproduction. Hum Reprod Update. 2008;14(4):293-307. https://doi.org/10.1093/humupd/dmn009.

37. Tosh D, Rao KL, Rani HS, Deenadayal DA, Murty US, Grover P. Association between fragile $X$ premutation and premature ovarian failure: a case-control study and meta-analysis. Arch Gynecol Obstet. 2014;289(6):1255-62. https:// doi.org/10.1007/s00404-014-3145-4.

38. Chatterjee S, Maitra A, Kadam S, Patel Z, Gokral J, Meherji P. CGG repeat sizing in the FMR1 gene in Indian women with premature ovarian failure. Reprod Biomed Online. 2009;19(2):281-6.

39. Asadi R, Omrani MD, Ghaedi H, Mirfakhraie R, Azargashb E, Habibi M, et al. Premutations of FMR1 CGG repeats are not related to idiopathic premature ovarian failure in Iranian patients: a case control study. Gene. 2018. https:// doi.org/10.1016/j.gene.2018.07.034

40. Ma Y, Wei X, Pan H, Wang S, Wang X, Liu X, et al. The prevalence of CGG repeat expansion mutation in FMR1 gene in the northern Chinese women of reproductive age. BMC Med Genet. 2019;20(1):81. https://doi.org/10.1186/ s12881-019-0805-z.

41. Huang W, Xia Q, Luo S, He H, Zhu T, Du Q, et al. Distribution of fragile X mental retardation 1 CGG repeat and flanking haplotypes in a large Chinese population. Mol Genet Genomic Med. 2015;3(3):172-81. https://doi.org/10. 1002/mgg3.128.

42. Tzeng CC, Tsai LP, Chang YK, Hung YJ, Chang YY, Su YP, et al. A 15-yearlong southern blotting analysis of FMR1 to detect female carriers and for prenatal diagnosis of fragile X syndrome in Taiwan. Clin Genet. 2017;92(2): 217-20. https://doi.org/10.1111/cge.12981.

43. Kim MJ, Kim DJ, Kim SY, Yang JH, Kim MH, Lee SW, et al. Fragile X carrier screening in Korean women of reproductive age. J Med Screen. 2013;20(1): 15-20. https://doi.org/10.1177/0969141313488364.

44. Hantash F, Goos D, Crossley B, Anderson B, Zhang K, Sun W, et al. FMR1 premutation carrier frequency in patients undergoing routine populationbased carrier screening: insights into the prevalence of fragile $X$ syndrome, fragile $X$-associated tremor/ataxia syndrome, and fragile $X$-associated primary ovarian insufficiency in the United States. Genet Med. 2011;13(1):39-45.

45. Gleicher N, Yu Y, Himaya E, Barad DH, Weghofer A, Wu YG, et al. Early decline in functional ovarian reserve in young women with low (CGGn < 26) FMR1 gene alleles. Transl Res. 2015;166(5):502-7.e1-2. https://doi.org/10. 1016/j.trsl.2015.06.014.

46. Barasoain M, Barrenetxea G, Huerta I, Telez M, Carrillo A, Perez C, et al. Study of FMR1 gene association with ovarian dysfunction in a sample from the Basque Country. Gene. 2013;521(1):145-9. https://doi.org/10.1016/j.gene. 2013.03.032.

47. Gleicher N, Weghofer A, Barad DH. Effects of race/ethnicity on triple CGG counts in the FMR1 gene in infertile women and egg donors. Reprod Biomed Online. 2010;20(4):485-91. https://doi.org/10.1016/j.rbmo.2009.12.017.

48. Arinami T, Asano M, Kobayashi $K$, Yanagi $H$, Hamaguchi $H$. Data on the CGG repeat at the fragile $X$ site in the non-retarded Japanese population and family suggest the presence of a subgroup of normal alleles predisposing to mutate. Hum Genet. 1993:92(5):431-6.

49. Elizur S, Lebovitz O, Derech-Haim S, Dratviman-Storobinsky O, Feldman B, Dor J, et al. Elevated levels of FMR1 mRNA in granulosa cells are associated with low ovarian reserve in FMR1 premutation carriers. PLoS One. 2014;9(8): e105121.

50. Wang Q, Barad DH, Darmon SK, Kushnir VA, Wu YG, Lazzaroni-Tealdi E, et al. Reduced RNA expression of the FMR1 gene in women with low $(C G G n<26)$ repeats. PLoS One. 2018;13(12):e0209309. https://doi.org/10.1371/journal. pone.0209309.

51. Conca Dioguardi C, Uslu B, Haynes M, Kurus M, Gul M, Miao DQ, et al. Granulosa cell and oocyte mitochondrial abnormalities in a mouse model 
of fragile X primary ovarian insufficiency. Mol Hum Reprod. 2016;22(6):38496. https://doi.org/10.1093/molehr/gaw023.

52. Ascano M, Mukherjee N, Bandaru P, Miller JB, Nusbaum JD, Corcoran DL, et al. FMRP targets distinct mRNA sequence elements to regulate protein expression. Nature. 2012;492(7429):382-6. https://doi.org/10.1038/ nature11737.

53. Mok-Lin E, Ascano M Jr, Serganov A, Rosenwaks Z, Tuschl T, Williams Z. Premature recruitment of oocyte pool and increased mTOR activity in Fmr1 knockout mice and reversal of phenotype with rapamycin. Sci Rep. 2018; 8(1):588. https://doi.org/10.1038/s41598-017-18598-y.

54. Lu C, Lin L, Tan H, Wu H, Sherman S, Gao F, et al. Fragile X premutation RNA is sufficient to cause primary ovarian insufficiency in mice. Hum Mol Genet. 2012;21(23):5039-47.

55. Sherman SL, Curnow EC, Easley CA, Jin P, Hukema RK, Tejada Ml, et al. Use of model systems to understand the etiology of fragile $X$-associated primary ovarian insufficiency (FXPOI). J Neurodev Disord. 2014;6(1):26. https://doi. org/10.1186/1866-1955-6-26.

56. Rehnitz J, Alcoba DD, Brum IS, Hinderhofer K, Youness B, Strowitzki T, et al. FMR1 and AKT/mTOR signalling pathways: potential functional interactions controlling folliculogenesis in human granulosa cells. Reprod Biomed Online. 2017;35(5):485-93. https://doi.org/10.1016/j.rbmo.2017.07.016.

\section{Publisher's Note}

Springer Nature remains neutral with regard to jurisdictional claims in published maps and institutional affiliations.

Ready to submit your research? Choose BMC and benefit from:

- fast, convenient online submission

- thorough peer review by experienced researchers in your field

- rapid publication on acceptance

- support for research data, including large and complex data types

- gold Open Access which fosters wider collaboration and increased citations

- maximum visibility for your research: over $100 \mathrm{M}$ website views per year

At $\mathrm{BMC}$, research is always in progress.

Learn more biomedcentral.com/submissions 